\title{
Broadening the participation and strengthening the unity
}

\author{
Angela Maria Alvarez', Lucília de Fátima Santana Jardim" \\ ' Federal University of Santa Catarina, Nursing Department. Florianópolis-SC, Brazil. President of the \\ Brazilian Nursing Association, 2013-2016 Management. Brasília-DF, Brazil. \\ "State Government of Amazonas, Foundation of Tropical Dermatology and Venereology Alfredo da Matta. \\ Manaus-AM, Brazil. Vice-President of the Brazilian Nursing Association, 2013-2016 Management. \\ Brasília-DF, Brazil.
}

The Board of Directors is inaugurating the new management in the Brazilian Nursing Association - National ABEn for the period 2013-2016. The Board of Directors that was sworn in on October 9, 2013, during the National Assembly of Delegates reaffirms the commitment of the Brazilian Nursing to remain aligned with the principles and purposes of the organization. Also, in relation to the history of struggle in order to contribute to the construction and consolidation of policies and programs that meet the desires and needs of the population. For all that the nursing represents and experiences, within the Brazilian society and the healthcare system, one wishes to articulate and maintain a fruitful dialogue with associations and specialist societies of Nursing and other areas. Also, with organs of the State and Social Control in order to fulfill our institutional and professional commitments, and positively influence the lives and health of people who are the subjects of the Nursing Care.

The reason makes us to believe that when a project is shared there is a chance to develop it in a much more robust and creative way because the possibilities multiply, and this facilitates the achievement of the goals. For this motive, the ABEn Program of Work elected the topic Broadening the participation and strengthening the unity, for 2013-2016 management. The experience in the ABEn reveals to us that the work is immense and only a dynamic and extended team, but strengthened in the unity, is going to fulfill all the commitments of the entity. So, stimulating and broadening the ABEn members participation is going to turn us into multipliers agents capable of transforming the ideas and proposals gestated in a strong design to the Nursing, in the health scenario of the Brazilian population. We hope that the Scientific Departments, Interest Groups, Working Groups and Committees (permanent or temporary) participate by aggregating to the working plan of the new Board of Directors and Fiscal Council in order to form an expanded management team. Also, we call on every member, as well as the Directors of Sections and Regions of the ABEn, for a permanent and continuous construction of the entity, which is being carried out by other generations of nurses and, more recently, by our predecessors, during 87 uninterrupted years. This is, perhaps, the greatest challenge!

It is known that the first of the purposes of ABEn is to bring together Nurses, Technicians, Nursing Assistants, under graduation and professional education students in order to encourage the solidarity and cooperation among them. We think this is an easy task. However, running the ABEn is not restricted to this. According to the bylaws, running this entity means to promote and ensure the political, cultural and scientific-technical development of the members and, among other things, the education and scientific development is the main driving force to the ABEn.

Therefore, the ABEn is trying to defend the quality of Nursing Education, at all levels of training and continuing education. Then, it mobilizes and participates in the discussions needed to elicit changes and stimulate the improvement of pedagogical practices and teaching-learning processes in order to prepare the professional citizen.

Moreover, it defends the nursing workers actions in a context of partnership with Nursing national and international entities, and also, the organization of other health professionals. It also contributes to consolidate the Nursing work as a social practice that is essential to assist the users of the Health Unique System, the organization and operation of health services and actions in the country.

It also promotes, organizes and coordinates the traditional scientific-technical, cultural and political events - national and international - guided by ethical and humanistic principles, and seeking to meet the interests of 
nursing and society, in general, It constitutes an space for further reflection on key issues to the Nursing practice, the promotion of scientific production and cooperation among participants.

It is possible to continue the structure consolidation in a network established by the National ABEn with Sections, Regions and Centers, in a participant and supportive management committed to the guidelines of the Working Plan of the 2013-2016 Management, and with the provisions of the entity bylaws. In this structure and during the assignment, it will be necessary to define and assess the technical staff - professionals and executives - in order to improve the communication between the board members and managers of the entity, trying to fulfill the set goals and achieve the proposed objectives for management.

Being aware of old and new struggles, and the challenges they represent, it is possible to rely on the tireless work of a motivated Board of Directors, and one hopes to carry on this position with dignity in order to honor the Brazilian Nursing. 